\title{
Socioeconomic and country variations in knowledge of health risks of tobacco smoking and toxic constituents of smoke: results from the 2002 International Tobacco Control (ITC) Four Country Survey
}

\author{
M Siahpush, A McNeill, D Hammond, G T Fong
}

Tobacco Control 2006;15(Suppl III):iii65-iii70. doi: 10.1136/tc.2005.013276

See end of article for authors' affiliations

Correspondence to Mohammad Siahpush $\mathrm{PhD}$, Centre for Behavioural Research in Cancer, The Cancer Council Victoria, 100 Drummond Street, Carlton VIC 3053, Australia; mohammad.siahpush@ cancervic.org.au

Received 1 July 2005 Accepted 30 November 2005
Background: Socioeconomic status is strongly associated with smoking prevalence and social class differences contribute substantially to social inequalities in mortality. This research investigated socioeconomic and country variations in smokers' knowledge that smoking causes heart disease, stroke, impotence and lung cancer, that smoke contains cyanide, mercury, arsenic and carbon monoxide, and whether nicotine causes most of the cancer.

Methods: Data were from the International Tobacco Control (ITC) Four Country Survey, a cohort survey of over 9000 adult smokers from four countries: the United States, Canada, the United Kingdom, and Australia. Data were collected via telephone interviews in 2002.

Results: Higher education and income were associated with higher awareness. For example, the odds of knowing that smoking causes heart disease, stroke and lung cancer were respectively $71 \%, 34 \%$ and $83 \%$ larger for respondents with high versus low income. The odds of knowing that smoke contains cyanide, mercury, arsenic and carbon monoxide were respectively $66 \%, 26 \%, 44 \%$ and $108 \%$ larger for respondents with a university degree than those with a high school diploma or lower level of education. Results also revealed that awareness of harms of smoking was generally the highest in Canada and the lowest in the UK.

Conclusions: Lower socioeconomic status was associated with lower awareness of the harms of smoking and misunderstanding around nicotine. There is a need to improve knowledge of the dangers of smoking among the disadvantaged segments of the population.
$\mathrm{S}$ ocioeconomic status (SES) is strongly associated with smoking behaviour. ${ }^{1-4}$ Not only are social inequalities in smoking prevalence pervasive, but they have been widening in such countries as Australia, the UK, the USA, Spain, Italy and Denmark in the past few decades. ${ }^{15-11}$ Social class differences in smoking contribute substantially to social inequalities in mortality. ${ }^{1}$ Unless action is taken to address the high prevalence of smoking among lower SES groups, we can expect a future widening of social inequalities in health. Any such action requires knowledge of the pathways from SES to smoking behaviour. This study examines SES variations in knowledge of the health effects of smoking and thereby sheds light on the mechanism of the SESsmoking relationship.

Many theories of behaviour change rely on a person's risk awareness and access to information. ${ }^{12-14}$ Knowledge of the health effects of smoking is one of the possible prerequisites for quitting and is targeted by prevention programmes. ${ }^{12}$ In a study of 9500 employed men in the USA, Nourjah and colleagues reported that knowledge of smoking as a risk factor for heart disease was a significant predictor of being an ever-smoker, intention to quit, and having quit smoking. ${ }^{15}$ Risk perception is shaped by such factors as warning labels on and availability of tobacco products, health education in media, and pattern of use by celebrities. ${ }^{16}$ An Australian study revealed that health warnings (including information on carbon monoxide in cigarette smoke) on cigarette packs were associated with increased knowledge of the constituents of cigarette smoke and a reduction in cigarette consumption. ${ }^{17}$ In developed countries, the majority of people are aware of the association of smoking with heart disease and lung cancer. ${ }^{18}$ Awareness of the association of smoking and other conditions such as stroke and impotence (which directly affects only men) is less and rarely reported.

Less is known about smokers' knowledge of the constituents of tobacco smoke. Cigarette smoke contains numerous toxic chemicals such as carbon monoxide, cyanide and arsenic. Carbon monoxide is a major contributor to cardiovascular disease from smoking. It impairs oxygen transportation in the blood, thereby reducing the amount of oxygenated blood circulated to body organs and tissues. It is also strongly linked with the development of coronary heart disease. ${ }^{19}$ Cyanide released from a cigarette can be 160 times more than the level considered safe. It has a direct, harmful effect on the cilia, a part of the natural lung clearance mechanism in humans, thereby increasing the likelihood of developing disease. ${ }^{19}$ The risk indices of cyanide and arsenic, related to the cardiovascular system, are significant with just one cigarette per day. ${ }^{20}$ The few reports that assess smokers' awareness of these toxins in smoke suggest a very low level of awareness. ${ }^{21} 22$

The association between SES and knowledge of some of the health effects of smoking has been reported in the past. Nourjah and colleagues found that, in the USA, white-collar employees were more likely to be knowledgeable of the effect of smoking on heart disease. ${ }^{15}$ Ayanian used a sample of 737

Abbreviations: CATI, computer assisted telephone interviewing; ITC-4, International Tobacco Control Four Country Survey; SES, socioeconomic status 
smokers in the USA and reported that high education was related to a greater awareness that smoking increased the risk of myocardial infarction..$^{23}$ Similar findings about the association of education and occupation with the knowledge of heart disease are reported in Canada ${ }^{12}$ and Sweden. ${ }^{24}$ The few studies that have examined the association of SES with knowledge of lung cancer ${ }^{25}{ }^{26}$ and stroke ${ }^{27}$ suggest a positive relationship. There are no published studies on knowledge that smoking is a cause of impotence. Neither do we know of any studies on SES variations in knowledge of chemical constituents of smoke.

Given that having knowledge of the health effects of smoking is essential for behaviour change, an examination of socioeconomic differences in knowledge can help explain part of the pronounced SES differentials in smoking prevalence and cessation rates. The aim of this study was to use population data from the USA, UK, Canada and Australia, and investigate socioeconomic and country variations in smokers' knowledge that smoking causes heart disease, stroke, impotence and lung cancer, and that smoke contains cyanide, mercury, arsenic and carbon monoxide. We also examined SES and country variations in whether smokers thought nicotine causes most of the cancer. Nicotine is the addictive drug in cigarette smoke but there is no evidence that it causes cancer. Knowledge of this is important because nicotine replacement therapies are a proven effective therapy for smoking cessation, and if smokers believe nicotine causes cancer they are unlikely to want to use these treatments.

\section{METHODS}

We used data from the International Tobacco Control Four Country Survey (ITC-4). Participants were 9058 adult smokers ( 18 years or older, smoked more than 100 cigarettes in their life, and smoked at least once in the past 30 days) from one of four countries: Canada $(\mathrm{n}=2214)$, the United States $(\mathrm{n}=2138)$, the United Kingdom $(\mathrm{n}=2401)$, and Australia $(\mathrm{n}=2305)$. The ITC-4 cohort was constructed from probability sampling methods with telephone numbers selected at random from the population of each country, within strata defined by geographic region and community size. Eligible households were identified by asking a household informant the number of adult smokers. The next birthday method ${ }^{28}$ was used to select the respondent in households with more than one eligible adult smoker.

ITC-4 is standardised across the four countries: respondents in each country are asked the same questions, with only minor variations for colloquial speech. The survey was conducted using computer assisted telephone interviewing (CATI) software and was completed in two calls: a 10-minute recruitment call was followed one week later by a 40-minute main survey. In order to increase recruitment rates, ${ }^{29}$ participants were mailed compensation equivalent to US\$10 before completing the main survey. Interviews were conducted by two survey firms: Roy Morgan Research (Melbourne, Australia) surveyed Australian and UK respondents, and Environics Research Group (Toronto, Canada) surveyed Canadian and US respondents. All aspects of the interviewer training and calling protocol were standardised across the two survey firms and closely supervised by the ITC-4 team. The present analysis is limited to respondents from Wave 1, conducted between October and December 2002. A full description of the ITC-4 methodology, sample profile, and survey rates, including comparisons with national benchmarks, is available at http://www.itcproject.org (see also Thompson et $a l^{30}$ in this supplement). The present analysis is limited to daily smokers, whose characteristics are shown in table 1 .

Respondents were asked to state whether they believed smoking causes heart disease, stroke, impotence and lung cancer in smokers, and whether "the nicotine in cigarettes is the chemical that causes most of the cancer". They were also asked to state whether they believed any of the following chemicals were included in cigarette smoke: cyanide, mercury, arsenic and carbon monoxide. Response categories were "yes" and "no".

We used education and household income as SES indicators. Level of education consisted of three categories: high school diploma or lower; technical, trade school, community college, or some university; university degree.

\begin{tabular}{|c|c|c|c|c|}
\hline Variables & $\begin{array}{l}\text { USA } \\
n=2135\end{array}$ & $\begin{array}{l}\text { Canada } \\
n=2202\end{array}$ & $\begin{array}{l}\text { UK } \\
n=2376\end{array}$ & $\begin{array}{l}\text { Australia } \\
\mathrm{n}=2296\end{array}$ \\
\hline \% female & 46.4 & 45.9 & 49.9 & 44.6 \\
\hline \multicolumn{5}{|l|}{ Age (years) } \\
\hline $18-24$ & 15.5 & 14.3 & 14.2 & 17.2 \\
\hline $25-39$ & 31.1 & 33.7 & 33.4 & 35.5 \\
\hline $40-54$ & 35.9 & 34.9 & 28.5 & 32.1 \\
\hline $55+$ & 17.6 & 17.1 & 23.9 & 15.1 \\
\hline \multicolumn{5}{|l|}{ Education } \\
\hline Low & 45.2 & 47.6 & 63.4 & 67.8 \\
\hline Medium & 43.5 & 39.5 & 24.7 & 20.1 \\
\hline High & 11.3 & 12.9 & 11.9 & 12.1 \\
\hline \multicolumn{5}{|l|}{ Income } \\
\hline Low & 36.0 & 27.5 & 28.1 & 25.6 \\
\hline Medium & 34.9 & 36.5 & 33.7 & 34.8 \\
\hline High & 21.7 & 27.4 & 28.5 & 33.6 \\
\hline No information & 7.4 & 8.5 & 9.7 & 5.9 \\
\hline \multicolumn{5}{|l|}{ \% saying smoking causes: } \\
\hline Heart disease & 85.8 & 90.9 & 89.6 & 88.6 \\
\hline Stroke & 73.2 & 82.7 & 70.3 & 80.7 \\
\hline Impotence & 34.3 & 59.6 & 36.2 & 35.6 \\
\hline Lung cancer & 94.4 & 94.8 & 93.7 & 94.3 \\
\hline \% saying nicotine causes most of cancer & 44.2 & 40.7 & 49.4 & 44.8 \\
\hline \multicolumn{5}{|l|}{ \% saying tobacco smoke contains: } \\
\hline Cyanide & 51.7 & 71.9 & 25.1 & 44.3 \\
\hline Mercury & 17.1 & 26.0 & 11.0 & 16.7 \\
\hline Arsenic & 42.1 & 57.7 & 17.0 & 41.0 \\
\hline Carbon monoxide & 85.0 & 90.8 & 64.6 & 82.6 \\
\hline
\end{tabular}


Annual income was categorised into "under \$30 000", "\$30 000-\$59 999", and "\$60 000 and over" for the US, Canadian, and Australian samples. For the UK sample, we used the following categories: "£15 000 or under", " $£ 15001-$ $£ 30,000$ " and "£30 001 and over". These categorisation schemes resulted in a similar distribution across countries and approximated tertile divisions

The study protocol was cleared for ethics by the institutional review boards or research ethics boards in each of the countries: the University of Waterloo (Canada), Roswell Park Cancer Institute (USA), University of Illinois-Chicago (USA), University of Strathclyde (UK), and The Cancer Council Victoria (Australia).

Stata 7 was used for all statistical analyses. ${ }^{31}$ The analysis of predictors of the knowledge that smoking leads to impotence was performed on the subsample of men. Cases with missing data were excluded from analyses, except for income where missing data were modelled.

\section{RESULTS}

Table 1 provides sample characteristics for each country. About $10 \%$ or more of smokers did not believe that smoking causes heart disease. Over $20 \%$ and $40 \%$ did not believe smoking causes stroke and impotence, respectively. A sizeable minority in all countries (ranging from $41 \%$ in Canada to $49 \%$ in the UK) believed that nicotine causes most of the cancer. Awareness of some of the constituents of smoke was particularly low, especially in the UK. For example, only $11 \%$ and $17 \%$ of smokers in this country believed that smoke contains mercury and arsenic, respectively. Awareness of the harms of smoking was the highest in Canada. The UK had the lowest awareness for most knowledge items.

Table 2 presents bivariate relationships between each knowledge item and education and income, by country. For nearly all knowledge items, higher education and income levels were associated with higher awareness.

As shown in table 3, higher education was associated with higher awareness, and this relationship was significant for stroke, impotence and stating that nicotine in cigarettes causes most of the cancer. Higher income was significantly associated with higher awareness for all items except impotence. As was the case in bivariate results, respondents from Canada were more likely to be aware of the health consequences of smoking than any other country. Generally, respondents in the USA were least likely to have knowledge of the harms of smoking. There were no country interactions with SES indicators. Table 3 also reveals that the link between knowledge of health hazards of smoking decreases with age.

As shown in table 4, higher education was significantly associated with the knowledge that smoke contains cyanide, mercury, arsenic and carbon monoxide. Higher income was significantly associated with higher awareness of cyanide, but not of mercury and carbon monoxide. There was a significant country-income interaction in the regression model for arsenic. The odds ratios for medium and high income were significant in the USA and Canada. In the USA, these odds ratios were 1.24 (95\% confidence interval (CI)

Table 2 Distribution of knowledge of health effects of smoking and constituents of tobacco smoke by education and income*

\begin{tabular}{|c|c|c|c|c|c|c|c|c|c|}
\hline & \multicolumn{4}{|c|}{ Smoking causes: } & \multirow[b]{2}{*}{$\begin{array}{l}\text { Nicotine causes } \\
\text { most of cancer }\end{array}$} & \multicolumn{4}{|c|}{ Tobacco smoke contains: } \\
\hline & $\begin{array}{l}\text { Heart } \\
\text { disease }\end{array}$ & Stroke & Impotence & $\begin{array}{l}\text { Lung } \\
\text { cancer }\end{array}$ & & Cyanide & Mercury & Arsenic & $\begin{array}{l}\text { Carbon } \\
\text { monoxide }\end{array}$ \\
\hline \multicolumn{10}{|l|}{ USA } \\
\hline \multicolumn{10}{|l|}{ Education } \\
\hline Low & 83.7 & 71.6 & 33.7 & 93.5 & 50.8 & 45.9 & 15.1 & 39.1 & 81.7 \\
\hline Medium & 87.0 & 74.1 & 35.9 & 95.4 & 41.0 & 54.8 & 17.8 & 42.5 & 87.7 \\
\hline High & 88.8 & 76.4 & 31.0 & 93.6 & 30.0 & 62.8 & 22.3 & 52.3 & 88.0 \\
\hline \multicolumn{10}{|l|}{ Income } \\
\hline Low & 85.3 & 72.1 & 32.7 & 93.8 & 51.4 & 43.3 & 15.8 & 36.2 & 83.6 \\
\hline Medium & 87.1 & 74.3 & 36.9 & 96.0 & 43.4 & 52.8 & 16.7 & 42.5 & 86.8 \\
\hline High & 88.5 & 74.2 & 32.8 & 95.1 & 32.2 & 65.7 & 19.7 & 51.4 & 86.9 \\
\hline \multicolumn{10}{|l|}{ CANADA } \\
\hline \multicolumn{10}{|l|}{ Education } \\
\hline Low & 89.9 & 81.0 & 55.2 & 93.5 & 49.1 & 68.8 & 25.4 & 52.2 & 89.6 \\
\hline Medium & 91.5 & 84.5 & 62.4 & 95.9 & 33.5 & 75.3 & 26.6 & 62.4 & 92.2 \\
\hline High & 92.6 & 83.6 & 67.2 & 96.7 & 32.0 & 73.3 & 26.2 & 63.2 & 90.4 \\
\hline \multicolumn{10}{|l|}{ Income } \\
\hline Low & 87.2 & 79.2 & 54.9 & 93.2 & 45.7 & 67.8 & 25.7 & 49.6 & 91.9 \\
\hline Medium & 90.5 & 82.4 & 59.4 & 94.8 & 42.3 & 71.4 & 26.5 & 60.2 & 89.6 \\
\hline High & 95.2 & 87.6 & 65.3 & 97.4 & 31.6 & 77.7 & 27.1 & 65.0 & 91.4 \\
\hline \multicolumn{10}{|l|}{ UK } \\
\hline \multicolumn{10}{|l|}{ Education } \\
\hline Low & 88.5 & 69.2 & 32.2 & 92.7 & 55.8 & 21.5 & 10.0 & 14.7 & 58.6 \\
\hline Medium & 91.0 & 73.0 & 38.0 & 94.7 & 44.8 & 27.0 & 11.9 & 18.4 & 71.5 \\
\hline High & 92.2 & 70.6 & 53.9 & 96.8 & 25.3 & 40.0 & 13.9 & 26.8 & 82.6 \\
\hline \multicolumn{10}{|l|}{ Income } \\
\hline Low & 84.3 & 64.2 & 31.1 & 90.5 & 57.4 & 21.3 & 10.9 & 17.1 & 57.7 \\
\hline Medium & 91.5 & 74.7 & 35.8 & 95.7 & 47.3 & 26.4 & 11.1 & 17.1 & 65.9 \\
\hline High & 93.8 & 73.3 & 43.5 & 96.8 & 39.4 & 29.4 & 10.4 & 18.3 & 72.4 \\
\hline \multicolumn{10}{|l|}{ AUSTRALIA } \\
\hline \multicolumn{10}{|l|}{ Education } \\
\hline Low & 88.0 & 80.3 & 34.4 & 93.6 & 50.6 & 42.6 & 16.0 & 39.3 & 80.3 \\
\hline Medium & 90.4 & 80.8 & 34.8 & 95.5 & 34.2 & 43.9 & 17.4 & 44.7 & 85.9 \\
\hline High & 89.1 & 83.0 & 43.3 & 95.8 & 30.3 & 54.8 & 19.8 & 44.0 & 90.1 \\
\hline \multicolumn{10}{|l|}{ Income } \\
\hline Low & 85.9 & 78.4 & 35.6 & 91.6 & 51.9 & 41.4 & 19.3 & 37.9 & 80.6 \\
\hline Medium & 89.2 & 81.1 & 34.5 & 94.4 & 43.0 & 45.2 & 18.1 & 43.0 & 83.6 \\
\hline High & 91.1 & 83.6 & 37.3 & 96.5 & 40.1 & 48.0 & 13.2 & 43.5 & 84.0 \\
\hline
\end{tabular}

Source: Weighted data from International Tobacco Control Four Country Survey Wave 1, 2002.

${ }^{*}$ All numbers are percentages. 
Table 3 Adjusted odds ratios (95\% confidence intervals) from logistic regression of having knowledge that smoking causes selected diseases on sociodemographic covariates

\begin{tabular}{|c|c|c|c|c|c|}
\hline & \multicolumn{4}{|c|}{ Knowledge that tobacco causes: } & \multirow{2}{*}{$\begin{array}{l}\text { Nicotine cause of mos } \\
\text { cancers* }\end{array}$} \\
\hline & Heart disease & Stroke & Impotence & Lung cancer & \\
\hline \multicolumn{6}{|l|}{ Sex } \\
\hline Male & 1.00 & 1.00 & - & 1.00 & 1.00 \\
\hline Female & $1.02(0.89$ to 1.17$)$ & 1.20 (1.08 to 1.33$)$ & - & $1.13(0.94$ to 1.36$)$ & $0.82(0.75$ to 0.89$)$ \\
\hline \multicolumn{6}{|l|}{ Age } \\
\hline $18-24$ & 2.49 (1.97 to 3.15$)$ & $1.32(1.12$ to 1.57$)$ & $1.63(1.31$ to 2.04$)$ & 8.75 (5.60 to 13.69$)$ & 1.47 (1.26 to 1.71$)$ \\
\hline $25-39$ & $2.28(1.91$ to 2.74$)$ & $1.53(1.33$ to 1.76$)$ & $1.39(1.15$ to 1.68$)$ & 4.70 (3.62 to 6.09$)$ & 1.34 (1.18 to 1.52$)$ \\
\hline $40-54$ & $1.92(1.61$ to 2.28$)$ & 1.54 (1.34 to 1.77$)$ & 1.26 (1.05 to 1.52$)$ & 2.26 (1.83 to 2.79$)$ & $1.15(1.02$ to 1.30$)$ \\
\hline \multirow{2}{*}{\multicolumn{6}{|c|}{ Education }} \\
\hline & & & & & \\
\hline Low & 1.00 & 1.00 & 1.00 & 1.00 & 1.00 \\
\hline Medium & 1.13 (0.97 to 1.32$)$ & $1.12(1.00$ to 1.26$)$ & 1.11 (0.96 to 1.28$)$ & 1.14 (0.92 to 1.42 ) & 1.61 (1.46 to 1.78$)$ \\
\hline High & $1.14(0.91$ to 1.43$)$ & $1.15(0.97$ to 1.35$)$ & 1.51 (1.24 to 1.83 ) & 1.25 (0.91 to 1.73 ) & $2.36(2.04$ to 2.72$)$ \\
\hline \multicolumn{6}{|l|}{ Income } \\
\hline Low & 1.00 & 1.00 & 1.00 & 1.00 & 1.00 \\
\hline Medium & 1.21 (1.03 to 1.43$)$ & 1.17 (1.03 to 1.32$)$ & 1.10 (0.93 to 1.30$)$ & 1.34 (1.07 to 1.68$)$ & 1.24 (1.11 to 1.38$)$ \\
\hline High & $1.71(1.40$ to 2.08$)$ & $1.34(1.17$ to 1.54$)$ & $1.14(0.96$ to 1.36$)$ & $1.83(1.39$ to 2.41$)$ & $1.53(1.36$ to 1.72$)$ \\
\hline No info & $0.82(0.65$ to 1.04$)$ & $0.91(0.75$ to 1.10$)$ & $0.97(0.73$ to 1.29$)$ & 0.64 (0.48 to 0.84$)$ & $0.98(0.83$ to 1.16$)$ \\
\hline \multicolumn{6}{|l|}{ Country } \\
\hline USA & 1.00 & 1.00 & 1.00 & 1.00 & 1.00 \\
\hline Canada & $1.61(1.33$ to 1.95$)$ & 1.78 (1.54 to 2.07$)$ & 2.45 (2.04 to 2.94 ) & 1.16 (0.89 to 1.52$)$ & $1.13(1.00$ to 1.28$)$ \\
\hline UK & $1.57(1.30$ to 1.90$)$ & 0.90 (0.78 to 1.02$)$ & $1.12(0.93$ to 1.35$)$ & $1.12(0.87$ to 1.45$)$ & $0.81(0.71$ to 0.91$)$ \\
\hline Australia & $1.22(1.01$ to 1.47$)$ & 1.50 (1.29 to 1.73 ) & $1.10(0.91$ to 1.32$)$ & $0.92(0.70$ to 1.19$)$ & 0.96 (0.85 to 1.09 ) \\
\hline
\end{tabular}

Source: International Tobacco Control Four Country Survey Wave 1, 2002

*Odds ratios pertain to the odds of stating that nicotine does not cause most of the cancer.

1.00 to 1.52 ) and 1.62 (95\% CI 1.28 to 2.05 ), and in Canada, they were 1.40 (95\% CI 1.13 to 1.74 ) and 1.54 (95\% CI 1.22 to 1.95). There was no significant relationship between income and knowledge of arsenic in the UK and Australia. As was the case in bivariate results, respondents from Canada were most likely and those from the UK were least likely to be aware of toxic constituents of smoke. Table 4 also reveals that the knowledge of constituents of smoke decreases with age.

In analyses not shown here, we controlled for the number of cigarettes smoked per day and time to first cigarette after waking. None of the results reported above changed notably.

Table 4 Adjusted odds ratios ( $95 \%$ confidence intervals) from logistic regression of having knowledge that tobacco smoke contains selected chemicals on sociodemographic covariates

\begin{tabular}{|c|c|c|c|c|}
\hline & \multicolumn{4}{|c|}{ Knowledge that tobacco smokes contains: } \\
\hline & Cyanide & Mercury & Arsenic & Carbon monoxide \\
\hline \multicolumn{5}{|l|}{ Sex } \\
\hline Male & 1.00 & 1.00 & 1.00 & 1.00 \\
\hline Female & 0.81 (0.74 to 0.88$)$ & $0.80(0.72$ to 0.90$)$ & $0.74(0.68$ to 0.81$)$ & $0.70(0.62$ to 0.78$)$ \\
\hline \multicolumn{5}{|l|}{ Age } \\
\hline $18-24$ & 1.89 (1.61 to 2.22$)$ & $1.15(0.94$ to 1.40$)$ & 1.72 (1.47 to 2.03$)$ & 1.80 (1.46 to 2.22$)$ \\
\hline $25-39$ & 1.64 (1.44 to 1.88$)$ & $1.20(1.01$ to 1.41$)$ & 1.54 (1.34 to 1.77$)$ & $1.15(0.99$ to 1.34$)$ \\
\hline $40-54$ & $1.58(1.38$ to 1.80$)$ & $1.16(0.98$ to 1.38$)$ & $1.47(1.28$ to 1.69$)$ & $1.02(0.88$ to 1.19$)$ \\
\hline $55+$ & 1.00 & 1.00 & 1.00 & 1.00 \\
\hline \multicolumn{5}{|l|}{ Education } \\
\hline Low & 1.00 & 1.00 & 1.00 & 1.00 \\
\hline Medium & 1.28 (1.16 to 1.42$)$ & 1.09 (0.96 to 1.24$)$ & $1.30(1.17$ to 1.44$)$ & $1.61(1.41$ to 1.84$)$ \\
\hline High & $1.66(1.44$ to 1.91$)$ & $1.26(1.06$ to 1.50$)$ & 1.44 (1.25 to 1.66$)$ & 2.08 (1.71 to 2.54$)$ \\
\hline \multicolumn{5}{|l|}{ Income } \\
\hline Low & 1.00 & 1.00 & 1.00 & 1.00 \\
\hline Medium & 1.14 (1.02 to 1.28$)$ & $0.95(0.83$ to 1.10$)$ & 1.24 (1.00 to 1.52$)$ & $1.06(0.92$ to 1.21$)$ \\
\hline High & 1.31 (1.16 to 1.48$)$ & $0.85(0.73$ to 1.00$)$ & 1.62 (1.28 to 2.05$)$ & $1.11(0.96$ to 1.30$)$ \\
\hline No information & $0.93(.078$ to 1.12$)$ & $0.92(0.73$ to 1.16$)$ & $1.05(0.73$ to 1.51$)$ & $0.75(0.61$ to 0.92$)$ \\
\hline \multicolumn{5}{|l|}{ Country } \\
\hline USA & 1.00 & 1.00 & 1.00 & 1.00 \\
\hline Canada & $2.40(2.11$ to 2.73$)$ & 1.63 (1.40 to 1.89$)$ & 1.79 (1.45 to 2.21$)$ & 1.58 (1.31 to 1.91$)$ \\
\hline UK & $0.30(0.27$ to 0.35$)$ & $0.57(0.47$ to 0.68$)$ & $0.39(0.31$ to 0.50$)$ & $0.33(0.28$ to 0.38$)$ \\
\hline Australia & $0.70(0.62$ to 0.79$)$ & $0.93(0.79$ to 1.09$)$ & $1.13(0.91$ to 1.41$)$ & 0.79 (0.67 to 0.94$)$ \\
\hline Country*Income & - & - & & - \\
\hline Canada*Med & - & - & $1.13(0.84$ to 1.53$)$ & - \\
\hline Canada*High & - & - & 0.95 (0.68 to 1.32$)$ & - \\
\hline Canada*No info & - & - & $0.97(0.59$ to 1.59$)$ & - \\
\hline UK*Med & - & - & $0.69(0.48$ to 0.95$)$ & - \\
\hline UK*High & - & - & 0.50 (0.35 to 0.73$)$ & - \\
\hline UK*No info & - & - & $0.67(0.38$ to 1.19$)$ & - \\
\hline Australia*Med & - & - & $0.85(0.63$ to 1.14$)$ & - \\
\hline Australia*High & - & - & $0.60(0.44$ to 0.83$)$ & - \\
\hline Australia*No Info & - & - & $0.56(0.32$ to 0.97$)$ & - \\
\hline
\end{tabular}

Source: International Tobacco Control Four Country Survey Wave 1, 2002. 


\section{DISCUSSION}

We used nationally representative samples of smokers from the USA, Canada, the UK and Australia and showed that lower SES is associated with less knowledge of health effects of smoking and toxic constituents of smoke. Our findings about awareness of health effects were consistent with previous research, which was reviewed in the introduction. Ours was the first study to examine SES variations in awareness of toxins in smoke. We note the universality of our findings across the four study countries and hypothesise that similar social variations exist in other high-income countries.

Misapprehension about nicotine was common with over $40 \%$ of all smokers believing that nicotine causes most of the cancer. Nearly half of the smokers in the UK and the majority of smokers with low SES fostered this belief. It is important that such misunderstandings are corrected, as smokers who believe that nicotine is carcinogenic are unlikely to choose to use nicotine replacement therapies, which are proven treatments for stopping. It is possible that a small number of smokers believed that nicotine was playing a role in the development of cancer because of its role as the addictive substance keeping people smoking. Further research is needed to explore this.

SES variations in the knowledge that tobacco smoke contains mercury were small because few people were aware of the existence of this substance in tobacco smoke. Mass media campaigns or cigarette pack warning labels have not sufficiently highlighted the fact that tobacco smoke contains mercury. We note that generally education had a stronger effect than income, where knowledge was limited (for example, knowledge about impotence, cyanide, mercury, and nicotine as a cause of cancer), and a weaker effect than income, where knowledge was widespread (for example, knowledge about heart disease and lung cancer). The only knowledge item that did not conform to this pattern related to carbon monoxide. We speculate that when knowledge of the health effects of a substance first becomes available, higher educated groups gain that knowledge faster. They are better skilled to obtain information and use information technology, and have a wider knowledge of and access to sources of information.

It is notable that among the four countries, smokers in Canada had the highest level of awareness of the harms of smoking and toxic compounds in smoke. This is most likely due to the strong anti-smoking education campaigns in Canada. In 2001, Health Canada announced the commencement of a five-year $\$ 480$ million programme to bolster existing tobacco control campaigns. About $40 \%$ of the budget is allocated to mass media campaigns targeting Canadians of all ages. ${ }^{32}$ Canada has one of the most progressive warning labels on cigarette packs in the world. Under Canadian law, 16 rotated picture based warnings are required in the top 50\% of the front and back of the cigarette package. The graphic pictures include a diseased mouth, a lung tumour, a brain after a stroke, a damaged heart, and a limp cigarette as part of an impotence warning. In addition, there are 16 rotated interior messages. On the side of the package, there is a range of yields for six substances. Cigarette packs in the USA, UK and Australia contain text warnings. Graphic warnings are expected to be introduced in Australia within two years and in the UK within five years. Package warning labels for health effects and smoke constituents have been linked to greater health knowledge among Canadian, US, UK, and Australian smokers (see Hammond et $a^{33}$ in this supplement). Furthermore, research might examine SES differences in: knowledge of the health effects of the constituents of tobacco smoke; the health effect of environmental tobacco smoke; myths about smoking (for example, exercise or

\section{What this paper adds}

The majority of people are aware of the association of smoking with heart disease and lung cancer. Awareness that smoking causes other conditions such as stroke and impotence is rarely reported. Less is known about smokers' knowledge of the constituents of tobacco smoke. A few studies have examined the association of socioeconomic status (SES) with heart disease and lung cancer and have reported a positive relationship.

Higher education was associated with higher awareness that smoking causes heart disease, stroke, impotence and lung cancer. Higher education was also associated with the knowledge that smoke contains cyanide, mercury, arsenic and carbon monoxide. Results also revealed that awareness of harms of smoking was generally the highest in Canada and the lowest in the UK, which is most likely due to the strong anti-smoking education campaigns in Canada.

vitamins undo most smoking effects); and smokers' perception of their risk of developing smoking related diseases.

Knowledge acquisition and increases in knowledge are among the first steps in the process of behaviour change. ${ }^{34}$ This research suggests that the least educated and least well-off smokers are least aware of smoking harms. They are also the most addicted to nicotine ${ }^{135}$ and least likely to be able to quit. ${ }^{36}$ There is a need to improve knowledge of the dangers of smoking among the disadvantaged segments of the population. However, while knowledge is a prerequisite for behaviour modification, it would be naïve to assume that knowledge alone would lead to successful cessation. Qualitative research suggests that prevalence of smoking is higher and cessation rates are lower among lower SES groups partly because of lack of social support for quitting, having many friends who smoke, having little opportunity for respite, living in unsafe and unpleasant social environments, living in communities with pro-smoking norms, being isolated from mainstream antismoking norms, and because smoking can foster social participation and belonging. ${ }^{37}{ }^{38}$ Thus, lower awareness of the harms of smoking is only one of many reasons for the higher prevalence of smoking among lower SES groups. A successful tobacco control strategy for disadvantaged groups would need to address their life circumstances and social environment, in addition to educating them of the health consequences of smoking.

\section{ACKNOWLEDGEMENTS}

We wish to thank Karen Burns for her research assistance. This research was funded by grants from the US National Cancer Institute/NIH (from the Roswell Park Transdisciplinary Tobacco Use Research Center (TTURC), P50 CAll1236, and from ROl CAl00362), the Canadian Institutes for Health Research (57897), Robert Wood Johnson Foundation (045734), the Australian National Health and Medical Research Council (265903), Cancer Research U.K. (C312/ A3726), the Australian Commonwealth Department of Health and Ageing, the Centre for Behavioural Research and Program Evaluation of the National Cancer Institute of Canada/Canadian Cancer Society, the Canadian Tobacco Control Research Initiative, and the Victorian Health Promotion Foundation (VicHealth)
Authors' affiliations
M Siahpush, Centre for Behavioural Research in Cancer, The Cancer Council Victoria, Carlton, Victoria, Australia
A McNeill, Department of Epidemiology and Public Health, University College London, London, UK
D Hammond, Department of Health Studies and Gerontology, University of Waterloo, Waterloo, Ontario, Canada
G T Fong, Department of Psychology, University of Waterloo, Canada 
Competing interests: none declared

\section{REFERENCES}

1 Jarvis MJ, Wardle J. Social patterning of individual health behaviours: the case of cigarette smoking. In: Marmot M, Wilkinson RG, eds. Social determinants of health. Oxford: Oxford University Press, 1999.

2 Siahpush M. Socioeconomic status and tobacco expenditure among Australian households: results from the 1998-99 Household Expenditure Survey. J Epidemiol Community Health 2003:57:798-801.

3 Hymowitz N, Cummings KM, Hyland A, et al. Predictors of smoking cessation in a cohort of adult smokers followed for five years. Tob Control 1997;6/suppl 2):s57-s62.

4 Shohaimi S, Luben R, Wareham N, et al. Residential area deprivation predicts smoking habit independently of individual educational level and occupational social class. A cross sectional study in the Norfolk cohort of the European Investigation into Cancer (EPIC-Norfolk). J Epidemiol Community Health 2003;57:270-6.

5 Fernandez $\mathbf{E}$, Schiaffino, Garcia $M$, et al. Widening social inequalities in smoking cessation. J Epidemiol Community Health 2001;55:729-30.

6 Osler M, Prescott E, Gottschau A, et al. Trends in smoking prevalence in Danish adults, 1964-1994. The influence of gender, age, and education. Scand J Soc Med 1998;26:293-8.

7 Osler M, Gerdes LU, Davidsen M, et al. Socioeconomic status and trends in risk factors for cardiovascular diseases in the Danish MONICA population, 1982-1992. J Epidemiol Community Health 2000;54:108-13.

8 Marsh A, McKay S. Poor smokers. London: Policy Studies Institute, 1994.

9 White V, Hill D, Siahpush M, et al. How has the prevalence of cigarette smoking changed among Australian adults? Trends in smoking prevalence between 1980 to 2001. Tob Control 2003;12:67-74

10 Nelson DE, Emont SL, Brackbill RM, et al. Cigarette smoking prevalence by occupation in the United States. J Occup Med 1994;36:516-25.

11 Faggiano $F$, Versino E, Lemma P. Decennial trends of social differentials in smoking habits in Italy. Cancer Causes Control 2001;12:665-71.

12 Potvin L, Richard L, Edwards AC. Knowledge of cardiovascular disease risk factors among the Canadian population: relationships with indicators of socioeconomic status. Can Med Assoc J 2000;162(9 suppl):S5-11.

13 Janz N, MH B. The health belief model: a decade later. Health Educ $Q$ $1984 ; 11: 1-47$

14 Bandura A. Self-efficacy: toward a unifying theory of behavioral change. Psychol Rev 1977;84:191-215.

15 Nourjah P, Wagener DK, Eberhardt $M$, et al. Knowledge of risk factors and risk behaviours related to coronary heart disease among blue and white collar males. J Public Health Policy 1994; 15:443-59.

16 Malone RE, Yerger V, Pearson C. Cigar risk perceptions in focus groups of urban African American youth. Journal of Substance Abuse $2001 ; 13: 549-61$

17 Borland R, Hill D. Initial impact of the Australian tobacco health warnings on knowledge and belief. Tob Control 1997:6:317-25.

18 Frank E, Denniston M, Pederson L. Declines in smokers understanding of tobacco hazards between 1986 and 1998: a report from North Georgia. South Med J 2002;95:675-80
19 Winstanley M, Woodward S, Walker N. Tobacco in Australia, facts and issues 1995, 2nd ed. Melbourne: Victorian Smoking and Health Program, Australia (Quit Victoria), 1995.

20 Fowles J, Dybing E. Application of toxicological risk assessment principles to the chemical constituents of cigarette smoke. Tob Control 2003;12:424-30.

21 Stockwell TR, Rutley R, Clark K. Pesticides and other chemicals in cigarette tobacco. Med J Aust 1992;157:68

22 Mullins R, Borland R. Evaluation of the 'What's your poison?' campaign. In: Mullins R, ed. Quit evaluation studies No, 6, 1990-1991. Melbourne: AntiCancer Council of Victoria, 1992.

23 Ayanian JZ, D CP. Perceived risks of heart disease and cancer among cigarette smokers. JAMA 1999:281:1019-21.

24 Andersson P, Leppert J. Men of low socio-economic and educational level possess pronounced deficient knowledge about the risks factors related to coronary heart disease. J Cardiovasc Risk 2001;8:371-7.

25 Price JH, Everett SA. Perceptions of lung cancer and smoking in an economically disadvantaged population. J Community Health 1994; 19:361-75.

26 Nobile CGA, Anfosso R, Pavia M, et al. Cigarette smoking: knowledge, attitudes and behaviour in an adult population in Italy. Public Health 2000;114:348-52.

27 Reeves MJ, Hogan JG, Rafferty AP. Knowledge of stroke risk factors and warning signs among Michigan adults. Neurology 2002;59:1547-52.

28 Binson D, Canchola JA, Catania JA. Random selection in a national telephone survey: a comparison of the Kish, next-birthday, and last-birthday methods. J Off Stat 2000;16:53-60.

29 Singer E, van Hoewyk J, Maher MP. Experiments with incentives in telephone surveys. Public Opin Q 2000;64:171-88.

30 Thompson ME, Fong GT, Hammond D, et al. Methods of the International Tobacco Control (ITC) Four Country Survey. Tob Control 2006; 15(suppl III):iii12-18.

31 StataCorp. Stata Statistical Software: Release 7.0, special edition. College Station, Texas: Stata Corporation, 2002.

32 Canada H. Health Canada's Tobacco Control Strategy, 2001. 2004; http:// www.hc-sc.gc.ca/(Accessed Feb 2004).

33 Hammond D, Fong GT, McNeill A, et al. Effectiveness of cigarette warning labels in informing smokers about the risks of smoking: findings from the International Tobacco Control (ITC) Four Country Survey. Tob Control 2006;15(suppl III):iii19-25.

34 Klesges RC, Somes G, Pascale RW, et al. Knowledge and beliefs regarding the consequences of cigarette smoking and their relationships to smoking status in a biracial sample. Health Psychol 1988;7:387-401.

35 Bobak M, Jha P, Nguyen S, et al. Poverty and smoking. In: Jha P, Chaloupka FJ, eds. Tobacco control in developing countries. Oxford: Oxford University Press, 2000.

36 Gilman SE, Abrams DB, Buka SL. Socioeconomic status over the life course and stages of cigarette use: Initiation, regular use, and cessation. J Epidemiol Community Health 2003;57:802-8

37 Stead M, MacAskill P, MacKintosh A, et al. "It's as if you're locked in": qualitative explanations for area effects on smoking in disadvantaged communities. Health and Place $2001 ; 7: 333-43$.

38 Stewart MJ, Brosky G, Gillis A, et al. Disadvantaged women and smoking Can J Public Health 1996;87:257-60. 